\title{
Targeting inflation in Asia and the Pacific: lessons from the recent past
}

\author{
Andrew Filardo ${ }^{1}$ and Hans Genberg ${ }^{2}$
}

\section{Introduction}

Central banks in Asia and the Pacific have overwhelmingly chosen inflation as the principal objective of monetary policy. Some central banks have declared themselves to be inflation targeters, while others pursue their objective without referring to this particular label. Moreover, whether or not they refer to their strategy as inflation targeting, central banks in the region have chosen diverse approaches to achieving their inflation targets: for example with respect to how explicit the target is, the choice of inflation indicator, and the choice of instrument. All this suggests that the region is a good sample with which to examine the lessons from the experiences of central banks that have adopted formal inflation targeting and those with more eclectic approaches to targeting inflation.

To this end, we examine monetary policy institutional changes in Asia and the Pacific with a view to assessing whether these can be traced to subsequent inflation performance. Section 2 highlights trends in twelve regional economies toward greater central bank focus on inflation control, institutional independence and transparency over the past two decades. Contrasting the experiences of the six formal inflation targeting economies with those of the six others, Section 3 explores the impact of these trends on inflation dynamics and on private sector inflation expectation formation. Section 4 then addresses some policy implications associated with evolving views of inflation targeting in the region, and concludes that our results add to the growing body of evidence that formal inflation targeting is not the only monetary policy framework capable of delivering price stability; in other words, targeting inflation is important but there are many ways to skin that cat.

\section{Monetary policy objectives and institutional arrangements in Asia- Pacific}

\section{Objectives and strategies}

As shown in Table 1, all but one of the twelve central banks in the region have price stability as a target for monetary policy. While for a majority of them the target appears unambiguously to refer to domestic price stability, in the case of three central banks - the People's Bank of China, Bank Indonesia and Bank Negara Malaysia - the goal is stated as maintaining the stability of the value of the currency which could mean either the internal value in terms of goods and services, ie the price level, or the external value namely the

1 Head of Economics for Asia and the Pacific, Bank for International Settlements. The views expressed in this paper are those of the authors and do not necessarily represent the views of the Bank for International Settlements or the Hong Kong Monetary Authority. We thank Már Gudmundsson, James Yetman, Anella Munro and participants of the 6th Norges Bank Conference on Monetary Policy for helpful comments. We also thank Marek Raczko for superb research assistance.

2 Visiting Adviser, Bank for International Settlements. First draft of this paper was completed while this author held the position of Executive Director, Research at the Hong Kong Monetary Authority 
exchange rate. Bank Indonesia makes it explicit that the term refers to both aspects. Two central banks - the Reserve Bank of India and the Bank Negara Malaysia - state that an adequate supply of credit to the economy is also an explicit goal of the central bank. Finally, the Hong Kong Monetary Authority puts exclusive emphasis on exchange rate stability (vis-àvis the US dollar) and pursues this goal by means of a currency board arrangement.

Strategies adopted to achieve the objectives differ. Six central banks are self-proclaimed inflation targeters - the Reserve Bank of Australia, Bank Indonesia, the Bank of Korea, the Reserve Bank of New Zealand, Bangko Sentral ng Pilipinas, and the Bank of Thailand. While the Reserve Banks of Australia and New Zealand are "old hands" at inflation targeting having started in 1993 and 1990 respectively, the other four central banks are relative newcomers with South Korea starting in 1998, Indonesia and Thailand in 2000, and the Philippines in 2002. All inflation targeting central banks use an interest rate as the operating monetary policy target.

The Monetary Authority of Singapore has been described by outside observers as an inflation targeter, albeit following an unorthodox strategy in pursuing price stability by announcing the level as well as the rate of change of the target band for the nominal effective exchange rate of the Singapore dollar.

The People's Bank of China (PBC) uses growth rates of monetary aggregates as intermediate targets and typically employs several instruments in the implementation of its monetary policy - the exchange rate, the required reserve ratio, interest rates, open market operations. While it is undoubtedly the case that these instruments are not completely independent of each other, controls on the domestic financial system and on international capital flows arguably give the PBC additional degrees of freedom to implement its monetary policy.

\section{Central bank governance and independence}

The ability of a central bank to achieve its objective depends in part on the institutional environment in which it operates. A large literature has investigated the link between measures of economic performance - usually inflation - and various indicators of central bank governance and independence (CBGI). A general conclusion of this literature is that central bank independence tends to be associated with better inflation performance, although there is some evidence that this result applies to developed economies only (Cuikerman et al (1992)).

A recent paper in this genre focuses on Asia and the Pacific. ${ }^{3}$ Ahsan, Skully, and Wickramanayake (2008, ASW) study 36 countries in the region including 11 of the countries in our sample. ${ }^{4}$ The authors construct indices of CBGI using 27 different variables meant to capture different aspects of governance and independence. Apart from an overall index they tabulate indicators of (i) legal independence ["Legal" in the graphs that follow], (ii) political independence ["Political"], (iii) independence to pursue price stability as the main and sole objective ["Price stability"], (iv) independence to pursue exchange rate policy ["Forex policy"], (v) independence in the control of monetary policy instruments and non-obligation to finance government deficits ["Deficit finance"], and (vi) accountability and transparency ["Account. and transp."]. Using these indicators in regression analysis, the authors find that each of them is negatively associated with the inflation rate of the corresponding economy.

3 Fry (1996) is a forerunner in this respect.

4 Singapore is not included. Ahsan et al (2008) also contains an exhaustive survey of the literature relating $\mathrm{CBGI}$ and economic performance. 
Rather than pursuing the link between CBIG and macroeconomic performance in the region, we will examine the evolution of the ASW indices with a view to detecting any trend over time and to establishing whether there is any appreciable difference between inflation targeting central banks and the others. We will also look at whether the 1997-98 crisis in the region acted as a wake-up call for the authorities in the most affected countries in the sense that they altered the governance structure of their respective central banks after the crisis.

Graph 1 shows the overall value of the CBIG index for two years, 1996 and $2005 .{ }^{5}$ The first year is chosen to represent the situation before the Asian financial crisis and the second is the latest available value in the ASW data set. With the exception of India and New Zealand for which there is no change, all countries show some improvement over time. This is consistent with the notion that policymakers have at least in part accepted the view that greater central bank independence is desirable. The sets of bars on the right hand side of the graph show averages of five groups of jurisdictions: all jurisdictions in the sample, the inflation targeting countries, central banks that are not inflation targeters, the countries most affected by the Asian financial crises (Indonesia, South Korea, Malaysia, Philippines, and Thailand), and finally the "non-crisis" countries. These bars reveal that both inflation targeting and the crisis countries have experienced larger changes in the overall index than their respective counterparts. Graph 2 explores these differences at a more disaggregated level.

The bars in Graph 2 represent the change in the values of the indices from 1996 to 2005 for all countries, inflation targeting and non-inflation targeting countries, and crisis and non-crisis countries. The graph shows that there are improvements in all aspects of CBIG and all groups with the exception of the ability to pursue price stability in the non-inflation-targeting central banks. Particularly large increases are seen in (i) political independence in the crisis countries, (ii) in the ability to pursue price stability in inflation-targeting and crisis countries (note that there is a large overlap in these groups as the inflation-targeting classification is based on the situation in 2005), (iii) in the ability to independently determine exchange rate policy.

The differences across country groupings, not surprisingly, are also illuminating. Compared to their non-inflation targeting counterparts central banks which are inflation targeters have been given more independence to pursue price stability as the sole objective of monetary policy. In general, inflation targeting central banks have become more accountable and transparent relative to their non-inflation targeting colleagues. This latter finding is consistent with the notion that while greater accountability and transparency are desirable for all central banks (see Graph 2), they have been given particular emphasis in the context of inflation targeting monetary policy strategies. With respect to legal independence and the ability to set monetary policy independently from fiscal policy (the 'deficit finance' bars), the greatest changes have actually occurred for non-inflation targeting central banks, somewhat contrary to the idea that lack of fiscal dominance is particularly important for inflation targeting strategies. ${ }^{6}$

The difference in the $\mathrm{CBGI}$ indices for "old" inflation targeting countries in the region (Australia and New Zealand) and the newcomers were very large before the crises and have fallen substantially thereafter. ${ }^{7}$ This confirms that the introduction of inflation targeting coincided with a more general overhaul of the central banks' governance structure.

5 The overall value is the simple average of the six sub-indices. Corresponding graphs for the sub-indices are presented in an appendix.

6 This result is not the consequence of non-inflation targeting central banks catching up. On the contrary, they have a higher index both in 1996 and in 2005.

7 The only exception is the legal independence sub-index. 
A comparison of the crisis with the non-crisis countries confirms that the Asian financial crisis did seem to lead to particularly significant reforms in the areas of political independence and the ability to set price stability objectives. In the latter case, this was probably due to the overlap between crisis countries and new inflation targeting countries.

\section{Transparency}

Dincer and Eichengreen (2007) focus on the determinants and effects of central bank transparency in a large (100) sample of central banks from developed and developing economies including those in our sample. Their empirical analysis implies that greater transparency reduces inflation volatility and persistence. Focusing exclusively on central banks in the Asia-Pacific region, Filardo and Guinigundo (2008) offer a more recent assessment of the transparency and communication strategies based on a survey of the central banks themselves. The responses to the survey give a snapshot of current practices in the region and indicate that central banks use "a fairly sophisticated set of communication strategies...[reflecting]... the greater conscious effort within the policy making circle to clearly communicate policy-relevant information to financial markets, the media and the public at large." Although it does not contain an explicit comparison with past communication practices, the message of the Filardo-Guinigundo study is consistent with the statistics reported above which show a general increase over time in the transparency and accountability of central banks in Asia and the Pacific.

Finally it is of interest to note the study by Garcia-Herrero and Remolona (2008) which argues that central banks in Asia and the Pacific have learned to conduct policy so as to take advantage of the expectations channel of monetary policy, ie to become more transparent as to their future policy intentions. Their conclusion is based partly on the content of central banks' policy statements and partly on evidence showing that yield curves reflect expectations of future policy interest rates. Yet they also note that "policy statements still appear to contain a larger element of surprise than do macroeconomic news, suggesting that there is still scope for central banks in the region to communicate more effectively the way they interpret economic data and the strategies that guide their decisions."

\section{Summary}

Inflation control is the main objective of all but one of the central banks in the region but the strategies for achieving this objective varies. Half of the twelve central banks characterise their policy as one of inflation targeting, and use a short-term interest rate as the policy instrument. Other central banks, with the exception of the Hong Kong Monetary Authority, target inflation and use a more eclectic set of policy instruments.

Whether they are inflation targeters or "merely" target inflation, most central banks in the region have gained legal and/or political independence during the past decade. They have also seen improvements in other aspects of governance usually associated with enhanced ability to achieve inflation control.

While there are differences in the evolution of central bank independence and governance between the inflation targeting central banks and the other central banks in our sample, it is an open question whether these differences have resulted in differences in macroeconomic performance, in particular inflation performance, between the corresponding economies. In the next section we present evidence bearing on this question as well as on the more specific issue whether the adoption of inflation targeting as such confers some additional benefits. 


\section{Assessing the comparative performance of Asia-Pacific inflation targeters}

There is no doubt that inflation performance in inflation targeting countries in the region has been remarkable when compared to the pre-inflation targeting days. In this section, we examine various statistical measures of inflation stability to explore whether the adoption of explicit inflation targeting was particularly effective in achieving the goal of inflation control in the Asia-Pacific region. In addition to examining performances before and after the adoption of inflation targeting, we contrast the experiences in controlling inflation between inflation targeting and non-inflation targeting central banks in the region.

\section{Inflation performance amongst Asia-Pacific inflation targeting economies was strong}

For the inflation targeting central banks, two performance criteria are central: the achievement of their inflation targets and the reduction of inflation volatility (ie fostering inflation stability). Despite the challenging policy environment of the last several years, inflation targeting central banks have been able to avoid some of the inflation control problems they had experienced in the past.

With regard to hitting inflation targets, inflation performance can be assessed in a variety of ways. The most stringent is whether the numerical target was hit. Graph 3 illustrates that by this metric Asia-Pacific inflation targeters have been far from perfect. Nearly all the inflation targeting central banks breached the announced inflation targeting bands, with some of the deviations being quite large and persistent.

Such deviations from target, however, may be too strict a criterion for assessing performance. Indeed, inflation targeting central banks in the region have not generally defined success as always being at the target or even inside the target bands. Rather, the more conventional approach is to announce a target range over a medium-term horizon. For example, Australia's target range is $2-3 \%$ for headline CPI inflation "over the medium term", and Korea's is $2.5-3.5 \%$ in terms of a three-year average annual inflation for headline inflation. Operationally, central banks choose a path for policy rates that puts inflation on a general trajectory towards the middle of the inflation target range.

Using this looser criterion, one could reasonably argue that central banks in the region have achieved their respective goals. Graph 3 shows that inflation rates in the region have consistently gravitated to the centre of the target ranges whenever deviations arose. The success stands in stark contrast to the more volatile inflation behaviour prior to the adoption of inflation targeting.

Notwithstanding this success, it is noteworthy that the deviations from the inflation targets have hardly been symmetrical. While there have been breaches both on the upside and the downside, most have been on the upside. Moreover, the biggest deviations from target have generally been on the upside.

There may be several explanations for this asymmetry. One view is that the period of inflation targeting has been so short that a full range of symmetric shocks, especially large and persistent ones, has yet to be experienced. This view would argue that more symmetry would be observed over time. Another view would suggest that, despite the constraining features of explicit inflation targeting frameworks, central banks are still relatively more concerned about subpar growth and deflation than periodic but modest breaches of the upper end of the target ranges. This would suggest that, on average, inflation would exceed the middle of the inflation target range.

Another performance criterion is inflation volatility. Here the record is far clearer. Inflation volatility generally declined across the region. Indeed, the GDP-weighted average of inflation volatility from 1986 to 1990 is 64\% higher than in 2008. 
Yet the decline in inflation volatility was hardly uniform across the region during the period. For example, the Philippines and New Zealand certainly achieved much better inflation performance with respect to this measure of volatility; however, Indonesia exhibited higher volatility after the adoption of inflation targeting than in the early 1990s, although part of the earlier stability may have been somewhat illusory because of the extensive use of administered prices for important staples

\section{Comparative performance with non-inflation targeters}

The experience of the non-inflation targeters over the same period is equally noteworthy. Inflation volatility for the non-inflation targeting central banks was either low or falling across the region. While this behaviour underscores the favourable inflation environment in the region as a whole, it does raise questions about the marginal contribution of explicit inflation targeting regimes in achieving this outcome. In other words, it is not clear that the adoption of inflation targeting per se has yielded inflation performance which is qualitatively different - at least with respect to the inflation volatility criterion - to that of the non-inflation targeting countries.

In terms of inflation levels, non-inflation targeting central banks have shown roughly the same success as inflation targeting central banks in achieving low inflation (Graph 4). For the non-inflation targeters, inflation rates were generally lower in the past 10 years than in the previous decade. Two notable exceptions to this trend toward greater success at controlling inflation are evident for inflation targeting and non-inflation targeting central banks alike: the Asian financial crisis in the late 1990s led to a spike in inflation, especially in Indonesia, Thailand and Korea; more recently, the boom and bust in commodity prices led to a transitory rise in inflation.

Another similarity between the inflation targeting and non-inflation targeting central banks is that short-term policy interest rates have become lower and smoother for those central banks using this rate as their primarily policy tool. In the 2000s, most policy interest rate cycles exhibited lower frequency swings than in the 1980s and early 1990s. This central bank behaviour was seen well beyond the region and was consistent with greater central bank transparency as documented in the previous section. The greater clarity about the goals and policy frameworks of central banks has been seen as elevating the role of private sector expectations in influencing economic decisions (Woodford, 2003). The similarity in behaviour across inflation targeting and non-inflation targeting central banks is consistent with the findings of Eijffinger and Geraats (2006) that remarkable enhancements of public communication during the period of 1998-2002 in central banks from advanced industrial economies were achieved without significant changes in formal disclosure policies in central bank legislation.

\section{Delving deeper into the inflation record}

Given the close comparative performance of the inflation targeters and the other central banks, we now delve more deeply into the characteristics of each country's inflation process to see if more subtle differences between inflation targeters and non-inflation targeters emerge. We first look at various measures of inflation persistence and examine how inflation persistence has evolved over time, focusing on the permanent and transitory components of the inflation process. Then we explore the implications of the choice of inflation targeting on private sector expectations, using panel regression methods. Theory would suggest that a significant change in monetary policy regimes, such as adopting explicit inflation targeting, should influence the time-series behaviour of inflation and the expectations of the private sector. 
$\mathrm{AR}(1)$ persistence measures. One conventional measure of persistence is the $\operatorname{AR}(1)$ parameter of an autoregressive representation of the inflation process, $\pi_{t}=C+\beta \pi_{t-1}+\zeta_{t}$. By this measure, persistence of the inflation process for inflation targeting appears to show a more systematic decline during the mid-1980s to mid-1990s period, relative to the 2000s (Graph 5). The average decline across the region for the inflation targeters from 0.4 to 0.1 understates the much more dramatic declines for Australia, Korea and New Zealand. These countries stand out in two respects. First, they are well developed, economically and financially, especially when compared to the rest of the Asia-Pacific region. Second, they adopted strong inflation targeting regimes. The Philippines, by way of contrast, is a small, open economy that has experienced much greater inflation variability. In Graph 5 (right side panel), the non-inflation targeting central banks have experienced very little change in the estimated AR(1) persistence across the two subperiods.

One interpretation of this result is that inflation expectations were more firmly anchored in some inflation targeting central banks. The firmer the anchor, the smaller the low-frequency drift in inflation expectations. Some conventional theories suggest that inflation represents a mixture of three stochastic processes:

$$
\pi_{t}=E\left(\pi_{t+1}\right)+\gamma y_{t}+\varepsilon_{t}
$$

For credible inflation targeters, expected inflation might be considered nearly a constant and $y$, the output gap, would be trendless (ie, an I(0) variable); the error term would be transitory white noise. In this case, actual inflation persistence would largely reflect the inherent persistence of the output gap. If, however, central banks were not so credible, then inflation expectations might move gradually up and down with the level of inflation. In this situation, the AR persistence would be higher than that implied by the output gap alone. From this vantage point, the decline in the AR persistence of the inflation targeting central banks could be seen as a sign of relative success in achieving inflation-fighting credibility. However, this cannot be the whole story because some economies characterised by a low AR persistence estimate, such as Indonesia and India, have relatively chequered records of inflation control.

To investigate the role of the persistent component in inflation expectations (ie the permanent stochastic component) and a transitory component (ie I(0) variables), we turn to an alternative measure of persistence along the lines of Stock and Watson (2007). While the full implementation of Stock and Watson's trend-cycle model proved to be unstable for many of the Asia-Pacific economies, a simplified integrated moving average $\operatorname{IMA}(1,1)$ representation fared much better.

In this implied IMA $(1,1)$ representation, changes in inflation from period to period are decomposed into two statistical components, one that arises from a shift in the permanent stochastic trend component of inflation and another one that arises from purely seriallyuncorrelated transitory fluctuations:

$\Delta \pi_{t}=a_{t}+\theta a_{t-1}=\Delta \tau_{t}+\Delta \eta_{t}$

Underlying this representation is a model of the level of inflation, $\pi_{t}=\tau_{t}+\eta_{t}$. The permanent component, $\tau_{t}$, is envisioned as evolving as a random walk, $\tau_{t}=\tau_{t-1}+\varepsilon_{t}$, with $\varepsilon_{t}$ and $\eta_{t}$ being serially, uncorrelated error terms. Under these assumptions, the statistical model of interest can be estimated as an $\operatorname{IMA}(1,1)$.

Some inferences about the relative role of the permanent and transitory components can be inferred from the MA estimate of $\theta$. If $\theta$ is close to zero, the permanent component plays a relatively large role in driving the inflation variance. The greater $|\theta|$, the greater the proportion of the inflation variance accounted for by the transitory component; intuitively, this would correspond to inflation fluctuating around its mean. 
Graph 6 plots the MA parameter estimates for the inflation targeting and non-inflation targeting economies. Various noteworthy features of the two panels stand out. First, the MA estimates are fairly large and the averages are between -0.5 and -1.0 for inflation targeting and non-targeting central banks alike. This suggests the role of permanent and transitory shocks is not particularly unique to whether a central bank chooses to explicitly adopt inflation targeting or not.

Second, for Australia, New Zealand and Korea, the absolute value of the MA estimate increases as might be expected with a successful inflation targeting regime. A time-varying measure of the MA parameter (not shown) confirms a nearly uniform change for each country since the end of the 1990s.

Third, a notable exception to the pattern observed for the inflation targeting economies is the Philippines. This appears to reflect the more challenging inflation conditions for this small, open economy. During the past decade, inflation rate swings have been pronounced and persistent, more often undershooting or overshooting the inflation target bands than remaining inside them. Moreover, the inflation target bands have been moved downwards during the decade, which could induce a bias towards a more prominent permanent component.

Fourth, for Indonesia and Thailand, the estimate of $\theta$ is nearly -1 and reflects the fairly favourable inflation behaviour before and after that tumultuous period ( $\mathrm{nb}$ the regression samples exclude the Asian financial crisis period in the late 1990s). Somewhat surprisingly, the MA estimate for Indonesia does not appear to have fallen even though inflation target bands have been both increased and then decreased over the past decade. This indicates that transitory shocks, often related to large relative price adjustments, have been a very important part of their inflation record.

Finally, Hong Kong and Singapore also stand out as having relatively low estimates of $\theta$. This might not be so surprising given their exchange rate regimes. Hong Kong adopted a currency board that has kept the bilateral exchange rate with the US dollar within a narrow corridor. Singapore, in contrast, controls its exchange rate against a trade-weighted basket of currencies of major trading partners; the Monetary Authority of Singapore uses this exchange rate as its policy tool to promote price stability and sustainable economic growth.

The technical nature of the discussion in this section should not obscure the basic point. The time-series econometric findings indicate that inflation performance has improved in the AsiaPacific region, and that improvements in regional price stability do not appear to correspond closely to the decision of some central banks to adopt formal inflation targeting.

\section{Exploring the cross-sectional dimension of inflation expectations}

While instructive, the time-series measures of inflation performance above are ex post realisations that may obscure some of the ex ante benefits of explicit inflation targeting. Indeed, one of the putative advantages of transparency associated with inflation targeting regimes is the self-reinforcing impact on private sector inflation expectations. Theory suggests that greater clarity about the intentions of a central bank should lead to reduced dispersion of private sector expectations, which in turn should promote the firmer anchoring of inflation expectations and hence greater inflation control. We explore this role of explicit inflation targeting in the Asia-Pacific region by comparing the impact of inflation targeting on the cross-sectional inflation expectations of the private sector using the survey by Consensus Economics.

\section{Does inflation targeting account for the narrowing of the forecast distributions?}

One natural question is whether shifts in the cross-sectional distribution of inflation forecasts are correlated in some way with the adoption of formal inflation targeting in the region. 
Graph 7 illustrates the shifts in the location as well as the shapes of the distributions. ${ }^{8}$ The estimated distributions represent the range of views that private sector forecasters held for inflation for the years 1996, 2001, 2006 and 2008 (the forecasters were surveyed in January of each preceding year).

Other things being equal, the adoption of inflation targeting should lead to a shift to the left, indicating a move to lower inflation, and a sharpening of the distribution, indicating less dispersion amongst the private sector forecasters. Indeed, this general tendency can be seen in the behaviour of the estimated cross-sectional distributions for the region. A few caveats are important to note.

First, we have data only from mid-1990 onwards owing to the data limitations of the Consensus Economics surveys. At the date that our data begin, both New Zealand and Australia had adopted explicit inflation targeting several years previously. For New Zealand, which adopted inflation targeting at an early stage, the cross-sectional distribution shifts somewhat to the right from 1996, reflecting the raising of the upper inflation range bound from $2 \%$ to $3 \%$ in the mid-1990s and the raising of the lower bound in the early 2000 s from $0 \%$ to $1 \%$. Notwithstanding the shift in the modes of the estimated distributions, the dispersion of inflation expectations has noticeably sharpened over time. For Australia, even though the inflation target bands did not change, the cross-sectional dispersion of inflation expectations sharpened too.

For Indonesia, Korea and Thailand which adopted inflation targeting in the 2000s, the shift in the mode of the cross-sectional distributions is much more dramatic. Also, there is less evidence of a uniform sharpening of the distributions.

Turning to the non-inflation targeting countries, the shifts and shape changes are much more diverse. For low-inflation economies such as Japan, Malaysia and Singapore, the crosssectional evidence does not appear to be out of line with the experiences of the inflation targeting countries. In general, there were fairly sharp distributions of inflation expectation with some shifting of their modes. For China, Hong Kong and India, there was a pronounced shift to the left after the mid-1990s. The dispersion for China and India remained fairly wide in the 2000s while Hong Kong has experienced periods of sharpness and periods of diffuse expectations. These results are also consistent with the findings of Mishkin and SchmidtHebbel (2006) that inflation targeting economies do not necessarily exhibit better monetary policy performance than highly successful non-inflation targeters.

Overall, the evolution of the private sector forecast distributions is consistent with the view that there has been a greater focus on inflation control in the region. To delve further into the links between these shapes of the forecast distributions and the monetary policy regime, it is important to distinguish the role of the regime from the size of the nominal shocks hitting the economy in each year. To achieve this, we now turn to panel regression methods.

\section{Econometric exploration of the dispersion of beliefs of private forecasters of inflation}

An immediate difficulty in assessing the statistical significance of the changing inflation forecast distributions lies in the conversion of the graphical shapes into a useful statistical metric. We use the Kullback-Liebler (KL) divergence metric. ${ }^{9}$ A higher $\mathrm{KL}$ statistic indicates a reduction in the dispersion of private sector views about the likely inflation outcomes, ie a sharper shape of the forecast distribution.

8 The distributions are estimated with kernel density estimators.

9 For more information about the methodology behind the KL statistic, see Filardo and Guinigundo (2008). 
Armed with these $\mathrm{KL}$ divergence statistics, we use panel regression analysis to examine the relationship between information in the $\mathrm{KL}$ divergence and the timing of the adoption of explicit inflation targeting regimes in the region. The estimated equation is

$$
K L n_{t}^{i}=C^{i}+\beta_{j} K L c_{t}^{i}+\gamma_{I T} I_{t}^{i}+\gamma_{A I T} \sum_{n=1}^{11} I_{t}^{n}+e_{t}^{i}
$$

where $K L n_{t, m}^{i}$ is the $K L$ divergence statistic that applies to the subsequent year's inflation forecast distribution for each country i reported in the month of $\mathrm{m}, K L c_{t, m}^{i}$ is a similar statistic for the current year's inflation forecast distribution, $I_{t}^{i}$ is a dummy variable that indicates whether a country $\mathrm{i}$ adopted a formal inflation targeting regime at time $\mathrm{t}$, and $\sum_{n=1}^{11} I_{t}^{n}$ is an aggregator of the inflation targeting dummy variables. In the reported results, we also allow for interactions between these dummy variables and the constant $(C)$ and slope parameters $\left(\beta_{j}\right)$. We use panel regressions with fixed effects and report the coefficient estimates along with t-statistics calculated with robust standard errors.

In Table 2, the results for the January Consensus Economics surveys are consistent with the view that the adoption of explicit inflation targeting was correlated with less dispersion of private sector forecasts of inflation. The coefficient estimates for $\mathrm{KL}$ levels have the intuitively plausible signs, and standard statistical diagnostics indicate a good fit.

The positive and statistically significant sign on $\operatorname{KLc}(\beta)$ reflects the fact that uncertainty about the inflation environment is seen to be fairly persistent from year to year. The estimate is robust to alternative specifications $2-5$ in Table 2.

The inflation targeting dummy coefficient $\left(\gamma_{I}\right)$ is statistically significant. The positive sign of the parameter in column (2) indicates that if a country is an inflation targeter, one-year-ahead inflation expectations are, on average, distributed with less dispersion, owing to the higher predicted KLn (of 0.21).

Inclusion of the inflation targeting aggregator dummy yields intriguing results. The aggregator dummy variable is a common regional dummy for all countries in the panel regression, which contrasts with the country-specific inflation targeting dummy $I_{t}^{i}$. The coefficient on the common aggregator dummy $\left(\gamma_{\text {AIT }}\right)$ in specifications $3-5$ in Table 2 is positive and statistically significant. The sign is intuitively plausible. As an indicator of the region's focus on inflation control, there was a general sharpening of private sector inflation forecast distributions. The coefficient may look rather small compared to the coefficient on the inflation targeting dummy variable but in the 2000s the value of the aggregator dummy is 5 (it is not 6 owing to the paucity of data for the Philippines); to get a sense of the quantitative importance in the 2000s, multiplying $\gamma_{A I T}$ by 5 is a useful benchmark.

In addition, the inclusion of the aggregator dummy variable in the panel regression leads to a reduction in the size and statistical significance of $\gamma_{I}$. The smaller size and lower statistical significance in specifications $4-5$ of $\gamma_{I}$ indicate that the aggregator dummy variable dominates the country-specific inflation targeting dummies.

These findings support the view that a common regional trend toward greater inflation control, as might be reflected in the aggregator dummy, could account for many of the similarities in inflation performance across the region. Such a view would downplay the importance of adopting explicit inflation targeting regimes as a necessary condition for 
improved inflation outcomes. ${ }^{10}$ This can be seen as being consistent with the basic conclusions of Ball and Sheridan (2003). They find evidence in OECD countries in favour of the hypothesis that greater emphasis on price stability, but not the adoption of inflation targeting per se, is important.

Specifications 6-7 include interactions between the country-specific and regional inflation targeting dummies with the slope estimates on $\Delta K L c_{t}^{i}$ (namely, $\beta_{I T}$ and $\beta_{\text {AIT }}$ ):

$$
\Delta K L n_{t}^{i}=C+\beta \Delta K L c_{t}^{i}+\gamma_{I T} I_{t}^{i}+\gamma_{A I T} \sum_{n=1}^{11} I_{t}^{n}+\beta_{I T}\left(I_{t}^{i} \times \Delta K L c_{t}^{i}\right)+\beta_{A I T}\left(\sum_{n=1}^{11} I_{t}^{n} \times \Delta K L c_{t}^{i}\right)+e_{t}^{i} .
$$

This first-difference specification is useful for examining the robustness of our conclusions from the panel regressions in levels. Intuitively, if central banks can more firmly anchor inflation expectations, inflation expectations at longer horizons should be less sensitive to transitory inflation shocks. In other words, the dispersion of inflation expectations for future years should be less variable to short-term inflation variability. In terms of the $\mathrm{KL}$ metric, this translates into a prediction that changes in KLn should become less sensitive to variations in $\mathrm{KLC}$ as central banks become more transparent and more interested in inflation stability. This prediction is borne out in Table 2 with $\beta_{A I T}$ being negative and statistically significant. This indicates that the slope of the relationship between $\Delta K L n_{t, m}^{i}$ and $\Delta K L c_{t, m}^{i}$ became flatter $\left(\beta+\beta_{\text {AIT }}\right)$ as the region as a whole became more focused on inflation control.

Taken as a whole, the panel results appear sufficiently strong to underscore the basic point that central banks in the region have been effective in getting out their message about price stability and, in the process, have had an important impact on private sector expectations. In turn, private sector expectations arguably have been supportive of the central bank price stability goals. ${ }^{11}$ Further research is needed to establish more subtle and possibly intricate inter-linkages among changing central bank practices and communication strategies, private sector expectations and macroeconomic stability.

Overall, the results confirm that greater emphasis on targeting inflation - though not explicit inflation targeting - has been important in the Asia-Pacific region. Central bank inflation fighting credibility appears to have generally risen, reflecting the intellectual, social and economic consensus that central banks control the inflation destiny of a country and that low, stable inflation promotes sustainable growth. But the initial motivation for this study remains an open empirical question: what is the marginal contribution of explicit versus implicit inflation targeting? The panel evidence in this section suggests that the contributions are not so obvious but subtle differences might be linked to the particular features of explicit inflation targeting regimes.

10 The basic thrust of the results using the aggregated IT dummies is obtained using the aggregated price stability and the monetary policy independence dummies described earlier in the paper, but with somewhat less statistical support. The results using the full sample of months from the Consensus Economics also is consistent with the results from the January sample.

11 The general narrowing of the forecast distributions could also correspond with biases amongst professional forecasters toward the benefits of formal inflation targeting, and hence the surveys could yield overly conservative dispersions of inflation forecasts. While possible, we also find some evidence in our sample that the reduction in dispersion is accompanied with an increased precision of forecasting accuracy, after correcting of the size of nominal shocks. 


\section{Conclusions from the empirical evidence}

The empirical evidence confirms that inflation performance in Asia and the Pacific has been admirable. The greater focus on inflation control has translated into a lower and more stable inflation environment.

However, it is difficult to document big differences in inflation performance over the past decade between explicit inflation targeters and non-inflation targeters. This is not to say there were no differences, but that the differences appear to be rather subtle.

Additional research and experience with inflation targeting will help to clarify the reasons for these performance patterns. In the interim, two competing, though not mutually exclusive, views are supportable. One view is that inflation dynamics in the region have been dominated by common nominal shocks. The swings in import prices during the mid-2000s and then the boom-bust cycle in global commodity prices toward the end of the 2000s surely left their imprint on the inflation record.

Another view emphasises the role of central bank mindsets. Over the past decades, central banks in the region and elsewhere saw a broad intellectual, social and economic consensus emerge about the importance of inflation control. Not only was low, stable inflation seen as a key policy goal but it was also felt that central banks had the means to achieve the goal.

In addition, supportive changes in central bank governance (as documented in Section 2) and in the general policy environment have taken place. Of particular importance in the past decade, Asia-Pacific policymakers strengthened medium-term policy frameworks, not least those associated with fiscal probity and financial stability. With respect to the fiscal side, the region has adopted sound fiscal practices that have strengthened sustainability and lowered debt levels. With respect to financial stability, the soundness of the region's banking system has been improved through prudent capital provisioning and the reduction in non-performing loans. These developments have not only strengthened the ability of central banks to achieve their primary goal of inflation control but have also helped to boost the public's confidence in the underlying competence of the region's policymakers.

Hence, the evidence from Asia-Pacific indicates there are many different ways to ensure price stability. In other words, there is more than one way to skin a cat.

\section{Policy implications and conclusions}

While the past decade has witnessed greater interest and determination in controlling inflation, thinking about the responsibilities of central banks continues to evolve. Exchangerate misalignments associated with periods of sustained capital inflows have long been of concern because of their impact on inflation and economic growth, and because of fears that the inflows may suddenly stop or reverse, leading to stress in local banking systems. ${ }^{12}$ The international financial crisis has naturally led even greater focus on the nexus of monetary stability and financial stability, not least owing to some views that the crisis could be attributed in part to lax monetary policy conditions during periods when inflation appeared to be consistent with medium-term trends. This section considers some challenges facing AsiaPacific central banks as they seek to maintain a primary focus on inflation in a context where concerns about financial system stability, the potential volatility of international capital flows and the variability of economic growth are taking on greater importance in the pursuit of central bank policy objectives.

12 See Committee on the Global Financial System (2009). 
Some would argue that pursuing multiple independent goals with monetary policy, ie with one policy interest rate, is futile or at least inadvisable. The classic assignment problem in macroeconomics emphasises the need for one independent policy tool for each independent policy goal. Moreover, others might argue that such competing goals would naturally lead to central banks to lose sight of their primary goal of price stability.

There are two basic counterarguments to this view. First, even though the logic of the assignment problem is impeccable, the theoretical assumptions are rather stark when compared to the practical trade-offs facing central banks. Goals related to financial, foreign exchange and capital flow volatility are not truly independent of the goal of price stability. Achieving price stability is a much more difficult task if stresses associated with these other factors are present in the economy. For example, if a strict focus on inflation control over a certain time horizon is associated with the buildup of imbalances in the economy that leads to inflation (or deflation) pressures further out in the future, then it may be argued that monetary policy faces a trade-off between near-term and longer-term inflation stability. Second, some central banks in the Asia-Pacific region have been able to achieve strong inflation performance while at the same time placing emphasis on exchange rate volatility, capital flows and financial stability concerns (eg India, Indonesia and China). This success should not be ignored. Indeed, with respect to exchange rate stability and inflation control Singapore and, of course, Hong Kong stand out.

This is not to say that central banks have an absolute or in most cases a comparative advantage in taking on these particular goals. But the experience in the region points out that one need not abandon inflation control when taking some actions to address these alternative, albeit subordinate, goals.

A key question is how best to incorporate these experiences from the region, and elsewhere, into our evolving understanding of the conduct of monetary policy. Is it necessary to construct monetary policy frameworks that focus exclusively on inflation control (as in strict inflation targeting regimes) or is it possible to construct monetary policy frameworks that reflect the wide range of trade-offs that central banks face? If so, what would these frameworks look like?

The answer to the questions depends on how central banks perceive their responsibilities outside strict inflation control. A few stylised approaches help to illuminate the key issues.

At one extreme is the view that central banks need to compartmentalise their policy priorities. A lexicographical approach provides a succinct way to summarise this perspective (Fischer, 2008). Under this view, central banks would target inflation, and only when inflation was under control would they take countercyclical actions intended to smooth output. Likewise, only when inflation and output stability was achieved would central banks entertain issues associated with exchange rates, capital flows and financial stability. While such priorities may have a theoretical appeal in certain stylised models of the economy, it is less clear that they are practicable in a context where the evolution of inflation, output and measures of financial stability depend on each other in a complex fashion. And, such a set of priorities appears to stand at odds with the actions taken by central banks during the international financial crisis.

An alternative approach is to smoothly trade-off output and inflation stabilisation, while emphasising key risks associated with auxiliary goals for a range of relevant policy horizons. As noted above, exchange rates, capital flows and financial stability issues have implications for inflation and output at some horizon. The policy conundrum is how best to weigh mediumto long-term concerns against those, say, at the 1-2 year horizon. One could interpret the fact that most central banks in the Asia-Pacific region have adopted price stability targets over the medium term as consistent with the view that strict inflation control at all horizons is not paramount, but rather that there are a range of concerns that need to be addressed. Finally, from technical point of view, such preferences may be best thought of as being statedependent (Svensson (2003), Disyatat (2005)). 
We would argue that the monetary policy responses in the region and elsewhere to the international financial crisis have been consistent with state-dependent preferences, but from a somewhat different motivation. Consider central banks that may find themselves in somewhat awkward positions at times when government authorities may not have adequately addressed regulatory or external issues, which then result in a crisis (Filardo, 2009). At that point, central banks may have a comparative advantage (in the short run) to address such concerns with monetary policy tools. Of course, central banks would prefer not to be in such a situation and certainly moral hazard issues arise. But, as the international financial crisis has shown, sometimes a central bank is called on to address such extreme situations. ${ }^{13}$

Practically, what might these state-dependent priorities mean for central banks, especially those with that have adopted strict inflation targeting in the past? One implication is that inflation targeting regimes need to be flexible. Overly strict, non-state-dependent criteria are not realistic.

Another implication is that conventional inflation targeting regimes and state-dependent priorities may be odd bedfellows. While it is possible to argue that flexible inflation targeting regimes can take into account economic and financial undershooting and overshooting, it is not so clear that stretching the reach of such policy regimes contributes in the best way to transparent and hence credible policymaking. Rather, monetary frameworks that explicitly reflect a full range of relevant policy risks would seem appropriate, especially given the different horizons that apply to short-term inflation and output fluctuations on the one hand and the longer-term boom-bust dynamics on the other. Frameworks such as those adopted by the Bank of Japan (two perspective approach) and the European Central Bank (two pillar approach) would appear more consistent with these types of concerns. In these regimes, there is a clear distinction between the inflation and output dynamics that economists have a reasonable handle on, and those phenomena that defy easy characterisation with conventional forecasting tools. In the case of the latter, the nature of the low probability-high impact risks are qualitatively different to the standard macro risks related to short-term inflation and output.

However, the suggestion that multi-pillar/perspective monetary policy frameworks should arguably dominate strict inflation targeting frameworks does not imply that one size fits all. Quite the contrary, a broader implication from the wide range of policy experiences in AsiaPacific is that monetary policy strategies may have to be tailored to each central bank depending on the nature of the economic environment. For example, instrument rules would naturally look different in different economies, depending on a diverse set of factors, not least being: whether the country is a commodity producer or not; the degree of exposure to food price shocks; the exposure to volatile international capital flows which in turn depends on the sophistication of the domestic financial system to deal with such shocks; openness and the role of the exchange rate in the inflation and growth process. These factors are furthermore likely to change over time, which means that monetary policy strategies cannot be static, even if the main objective of policy remains price stability.

13 In some respects, this motivation is one justification for central banks taking on the responsibility of lender of last resort. But recent central bank behaviour raises the practical question of whether the central bank should be lender of first resort, or somewhere in between. 
Table 1

\section{Central bank policy objectives}

\begin{tabular}{|c|c|c|c|}
\hline Central bank & Policy objective & ... as stated on the central bank's official website & IT? \\
\hline $\begin{array}{l}\text { Reserve Bank of } \\
\text { Australia }\end{array}$ & Price stability & $\begin{array}{l}\text {....to focus on price (currency) stability while taking account of the implications of monetary policy for activity } \\
\text { and, therefore, employment in the short term }\end{array}$ & $\begin{array}{l}\text { Yes, } \\
1993\end{array}$ \\
\hline $\begin{array}{l}\text { The People's Bank of } \\
\text { China }\end{array}$ & Value of the currency & $\begin{array}{l}\text { The objective of the monetary policy is to maintain the stability of the value of the currency and thereby } \\
\text { promote economic growth. }\end{array}$ & No \\
\hline $\begin{array}{l}\text { Hong Kong Monetary } \\
\text { Authority }\end{array}$ & Exchange rate stability & $\begin{array}{l}\text { The primary monetary policy objective of the Hong Kong Monetary Authority (HKMA) is to maintain } \\
\text { exchange rate stability }\end{array}$ & No \\
\hline $\begin{array}{l}\text { Reserve Bank of } \\
\text { India }\end{array}$ & $\begin{array}{l}\text { Price stability and } \\
\text { adequate credit supply }\end{array}$ & ...maintaining price stability and ensuring adequate flow of credit to productive sectors & No \\
\hline Bank Indonesia & $\begin{array}{l}\text { Price stability and } \\
\text { exchange rate stability }\end{array}$ & $\begin{array}{l}\text {... Bank Indonesia has one single objective of achieving and maintaining stability of the Rupiah value. The } \\
\text { stability of the value of the Rupiah comprises two aspects, one is stability of Rupiah value against goods } \\
\text { and services and the other is the stability of the exchange rate of the Rupiah against other currencies. }\end{array}$ & $\begin{array}{l}\text { Yes, } \\
2000\end{array}$ \\
\hline Bank of Japan & Price stability & $\begin{array}{l}\text { The Bank of Japan Law states that the Bank's monetary policy should be "aimed at, through the pursuit of } \\
\text { price stability, contributing to the sound development of the national economy." }\end{array}$ & No \\
\hline The Bank of Korea & Price stability & $\begin{array}{l}\text { Like other central banks, the Bank of Korea takes price stability as the most important objective of its } \\
\text { monetary policy. The Bank of Korea Act, which came into effect in April } 1998 \text { following its revision at the } \\
\text { end of 1997, stipulates price stability as the purpose of the Bank of Korea. }\end{array}$ & $\begin{array}{l}\text { Yes, } \\
1999\end{array}$ \\
\hline $\begin{array}{l}\text { Bank Negara } \\
\text { Malaysia }\end{array}$ & $\begin{array}{l}\text { Price stability and } \\
\text { exchange rate stability }\end{array}$ & $\begin{array}{l}\text { To issue currency and keep reserves safeguarding the value of the currency; To promote monetary stability } \\
\text { and a sound financial structure; To influence the credit situation to the advantage of the country. }\end{array}$ & No \\
\hline $\begin{array}{l}\text { Reserve Bank of New } \\
\text { Zealand }\end{array}$ & Price stability & $\begin{array}{l}\text { The Reserve Bank of New Zealand Act } 1989 \text { specifies that the primary function of the Reserve Bank shall } \\
\text { be to deliver "stability in the general level of prices." }\end{array}$ & $\begin{array}{l}\text { Yes, } \\
1990\end{array}$ \\
\hline $\begin{array}{l}\text { Bangko Sentral } \mathrm{Ng} \\
\text { Pilipinas }\end{array}$ & Price stability & $\begin{array}{l}\text { The primary objective of BSP's monetary policy is to promote a low and stable inflation conducive to a } \\
\text { balanced and sustainable economic growth. }\end{array}$ & $\begin{array}{l}\text { Yes, } \\
2002\end{array}$ \\
\hline $\begin{array}{l}\text { Monetary Authority of } \\
\text { Singapore }\end{array}$ & Price stability & $\begin{array}{l}\text { The primary objective of monetary policy in Singapore is to promote price stability as a sound basis for } \\
\text { sustainable economic growth. }\end{array}$ & No \\
\hline Bank of Thailand & Price stability & $\begin{array}{l}\text { Setting the monetary policy direction which is consistent with the nation's economic conditions, with the } \\
\text { ultimate objective of maintaining price stability and sustainable economic growth }\end{array}$ & $\begin{array}{l}\text { Yes, } \\
2000\end{array}$ \\
\hline
\end{tabular}


Table 2

The impact of the adoption of inflation targeting on the cross-sectional distribution of inflation forecasts in Asia-Pacific

$$
K L n_{t}^{i}=C^{i}+\beta K L c_{t}^{i}+\gamma_{I T} I_{t}^{i}+\gamma_{A I T} \sum_{n=1}^{11} I_{t}^{n}+\beta_{I T}\left(I_{t}^{i} \times K L c_{t}^{i}\right)+\beta_{A I T}\left(\sum_{n=1}^{11} I_{t}^{n} \times K L c_{t}^{i}\right)+e_{t}^{i}
$$

\begin{tabular}{|c|c|c|c|c|c|c|c|}
\hline & \multicolumn{7}{|c|}{ Using January sample } \\
\hline & (1) & (2) & (3) & (4) & (5) & (6) & (7) \\
\hline & \multicolumn{5}{|c|}{$\mathrm{KL}$ in levels } & \multicolumn{2}{|c|}{$\Delta \mathrm{KL}$} \\
\hline$\beta$ & $.62(6.8)$ & $.61(6.8)$ & $.57(6.1)$ & $.57(6.1)$ & $.58(4.7)$ & $.87(4.6)$ & $.86(4.6)$ \\
\hline$\gamma_{I T}$ & & $.21(4.2)$ & & $.06(0.9)$ & $.01(0.6)$ & & $.17(2.2)$ \\
\hline$\gamma_{A I T}$ & & & $.05(2.8)$ & $.05(2.1)$ & $.05(2.1)$ & & $-0(-0.5)$ \\
\hline$\beta_{I T}$ & & & & & $-04(-0.3)$ & $-13(-0.8)$ & $-13(-0.8)$ \\
\hline$\beta_{\text {AIT }}$ & & & & & & $-08(-1.9)$ & $-08(-1.9)$ \\
\hline Nobs & 163 & 163 & 163 & 163 & 163 & 149 & 149 \\
\hline$R^{2}$ & .66 & .66 & .66 & .67 & .67 & .34 & .34 \\
\hline
\end{tabular}

Notes: t-statistics in parentheses based on robust standard errors. 
Graph 1

Index of central bank independence and governance ${ }^{1}$

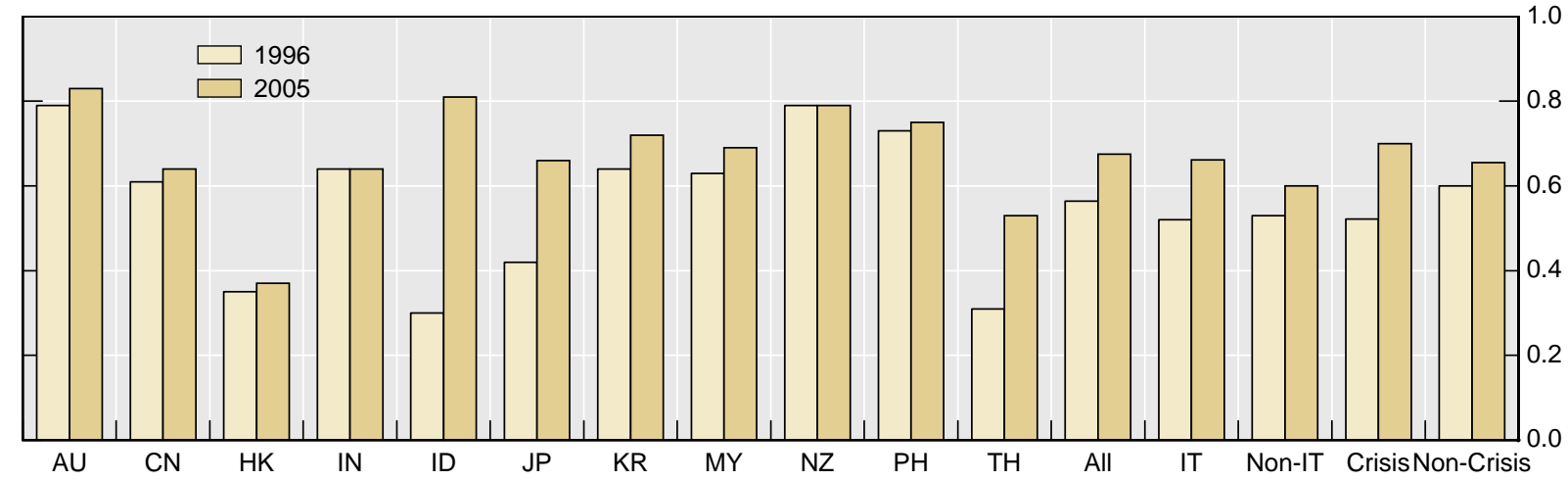

$\mathrm{AU}=$ Australia; $\mathrm{CN}=$ China; $\mathrm{HK}=$ Hong Kong; $\mathrm{ID}=$ Indonesia; $\mathrm{IN}=$ India; JP = Japan; $\mathrm{KR}=\mathrm{Korea} ; \mathrm{MY}=$ Malaysia; NZ = New Zealand; $\mathrm{PH}=$ Philippines; $\mathrm{TH}=$ Thailand; All = Average for all countries; $\mathrm{IT}=$ Average for inflation targeting countries; Non-IT = Average for non inflation targeting countries; Crisis = Average for Indonesia, South Korea, Malaysia, Philippines, and Thailand; Non-Crisis = Average for Australia, China, Hong Kong, India, Japan and New Zealand.

1 There were no data available for Singapore.

Source: Ashan et al (2008)

\section{Graph 2}

\section{Differences in the overall index between 2005 and 1996}

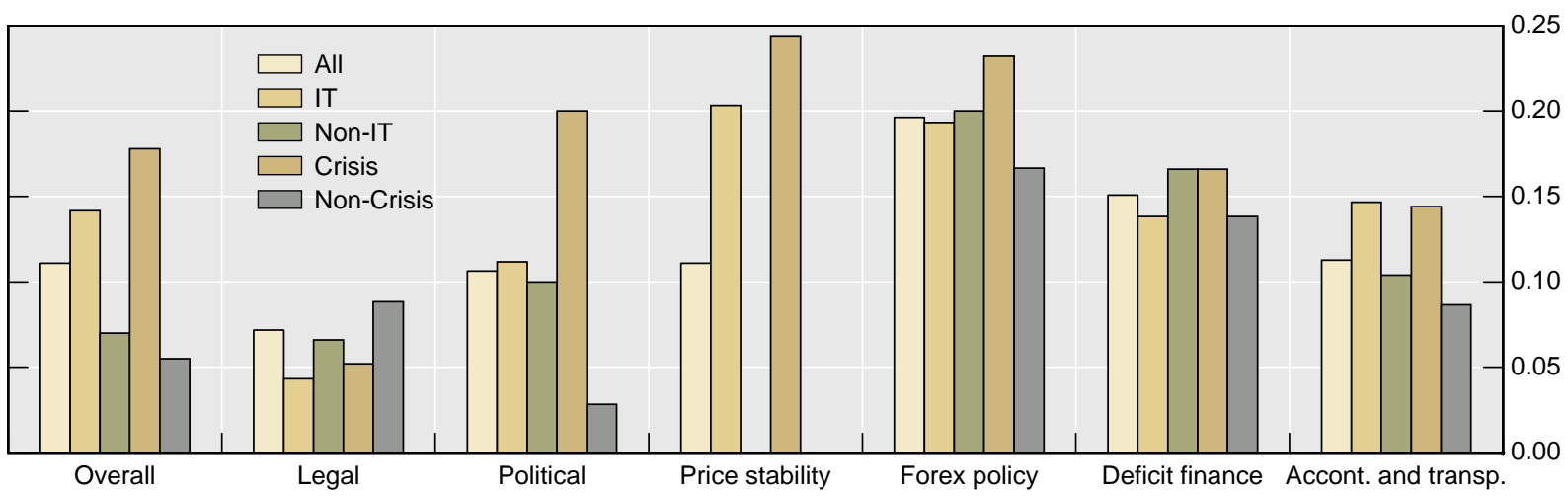

Source: Ashan et al (2008) 


\section{Graph 3}

\section{Inflation1, inflation targets and policy rates2}

Australia

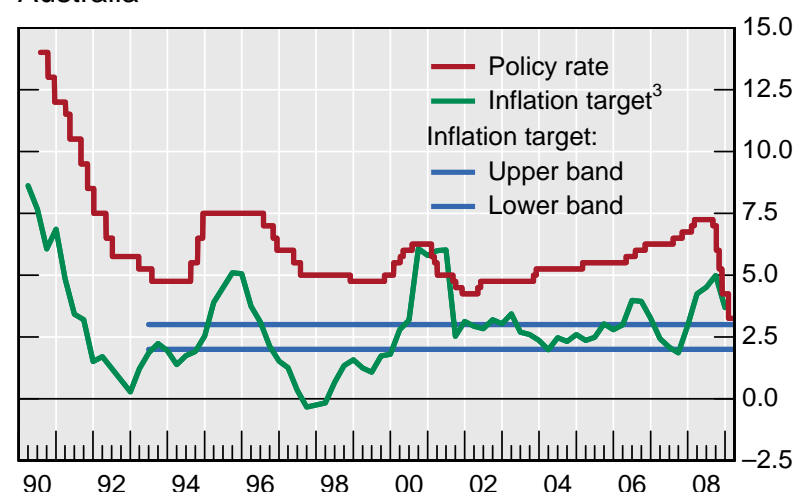

Korea

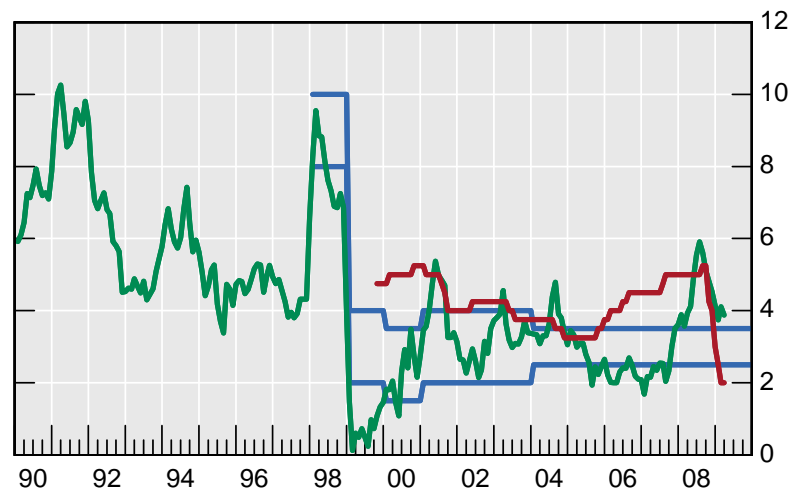

Philippines

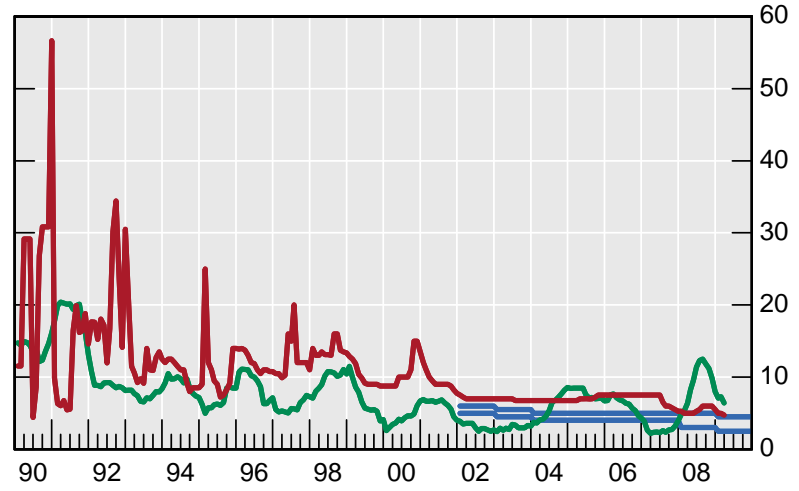

Indonesia

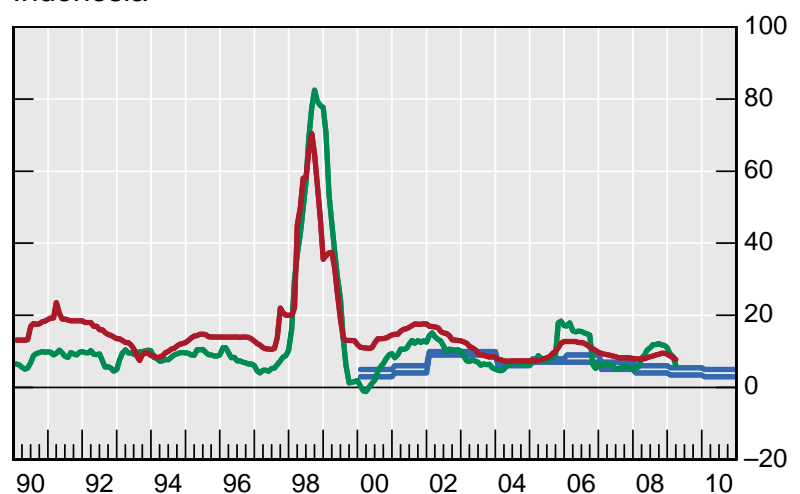

New Zealand

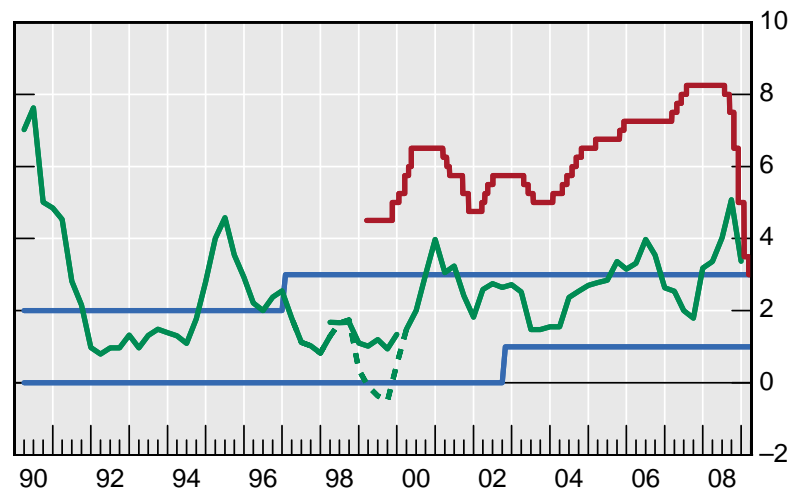

Thailand

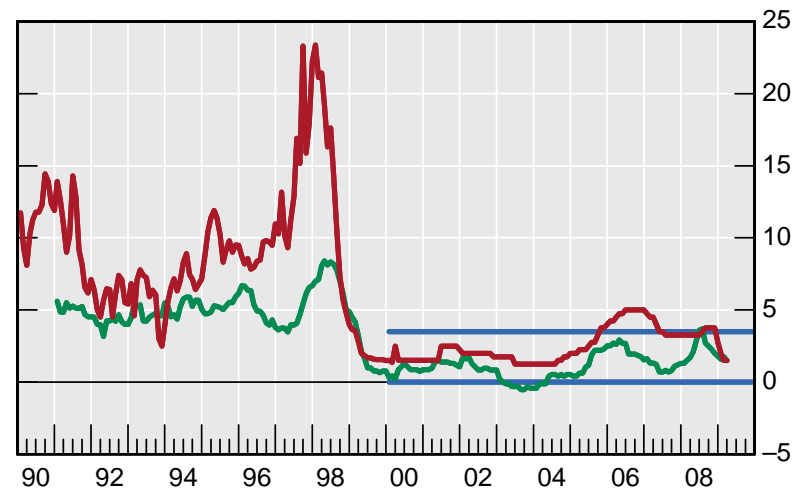

1 Twelve-month changes in consumer prices. ${ }^{2}$ Per cent per annum. ${ }^{3}$ In terms of headline consumer prices index, except in the case of Thailand, where it refers to core inflation. Between 1998 and 1999 New Zealand was monitoring the consumer prices index excluding credit services.

Sources: CEIC; national data. 


\section{Graph 4}

\section{Inflation $^{1}$ and benchmark rates ${ }^{2}$}

China

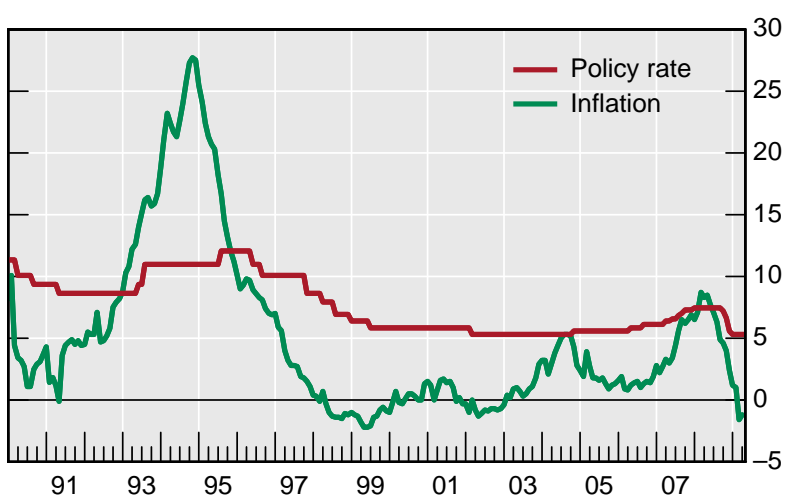

India

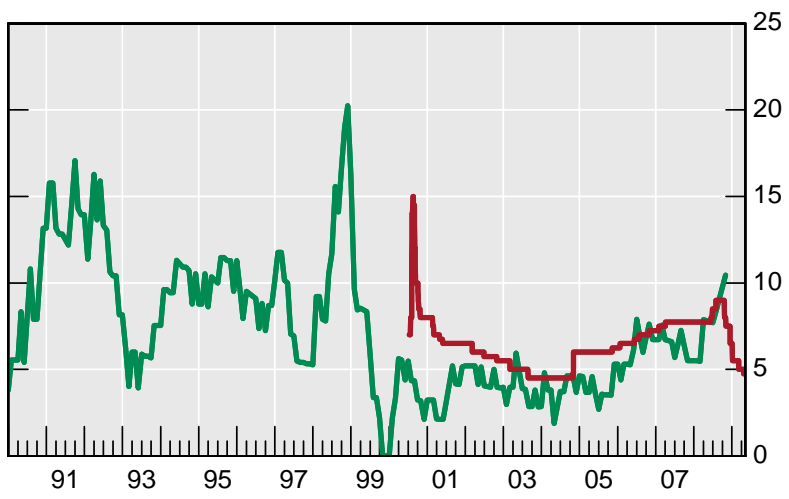

Malaysia

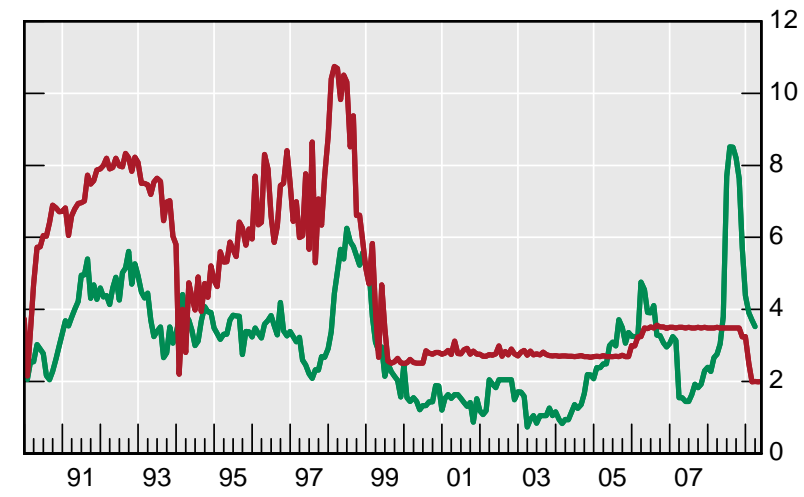

Hong Kong SAR

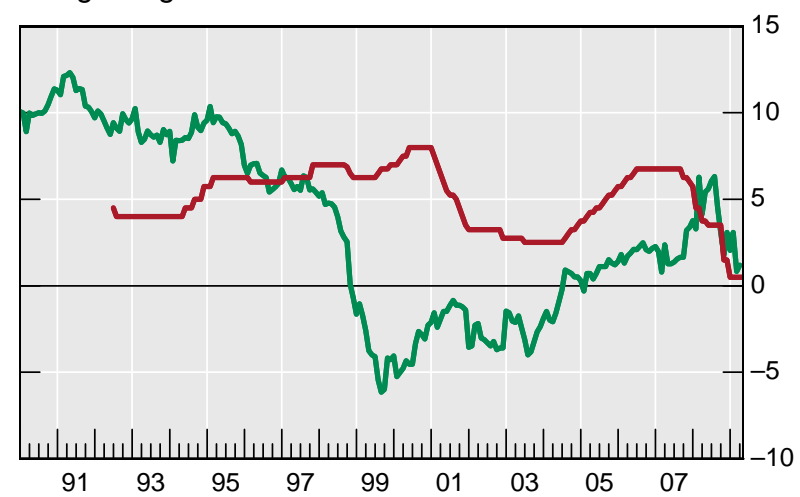

Japan

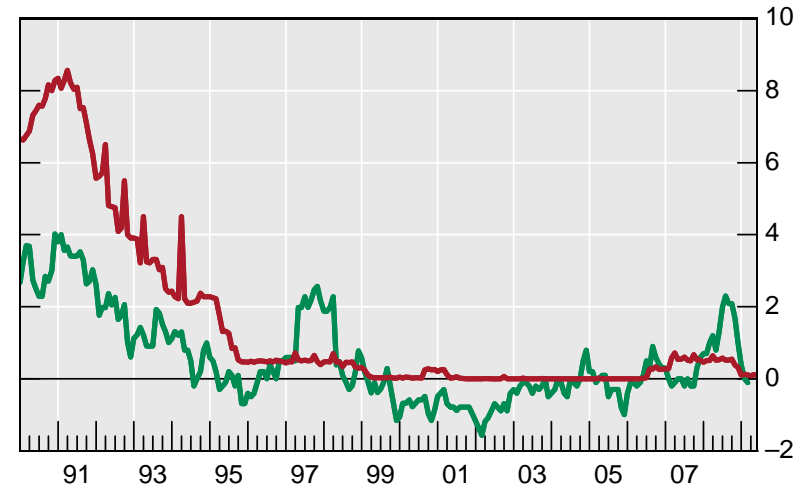

Singapore

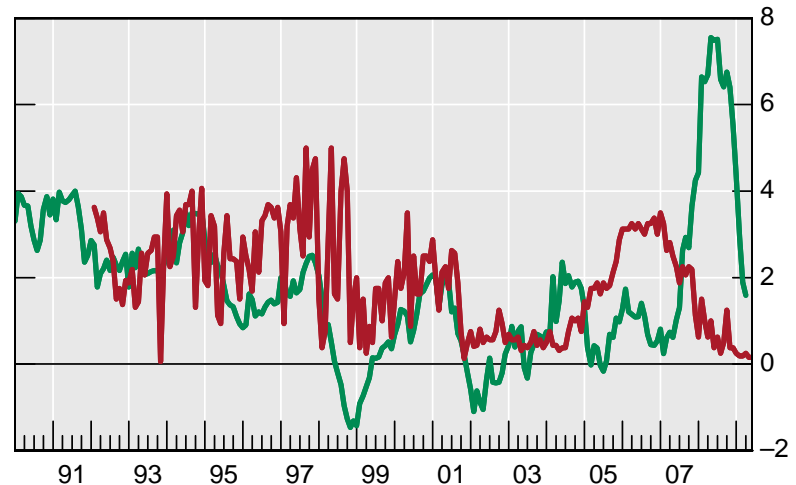

1 Twelve-month percentage changes in consumer prices. ${ }^{2}$ Per cent per annum. China: one-year working capital; Hong Kong SAR: discount window base rate; Japan: uncollateralized overnight rate; India: repo rate; Malaysia: overnight interbank rate; Singapore: overnight rate,

Sources: Datastream; national data. 


\section{Graph 5}

\section{Changing $A R(1)$ inflation persistence ${ }^{1}$}

Inflation targeters

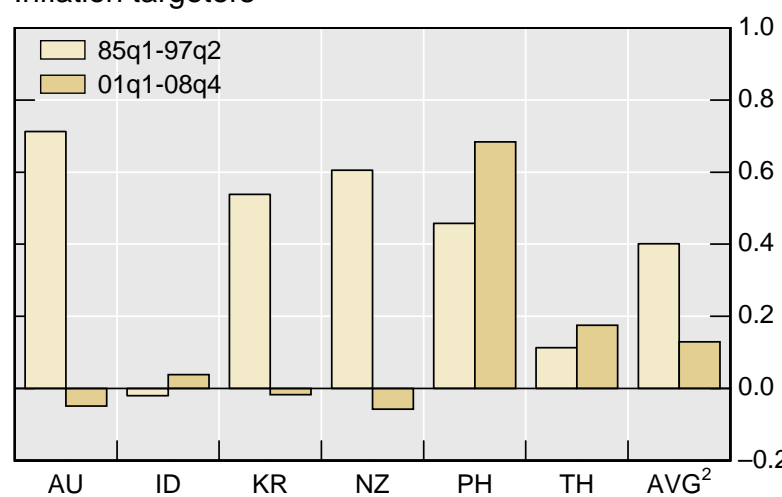

Others

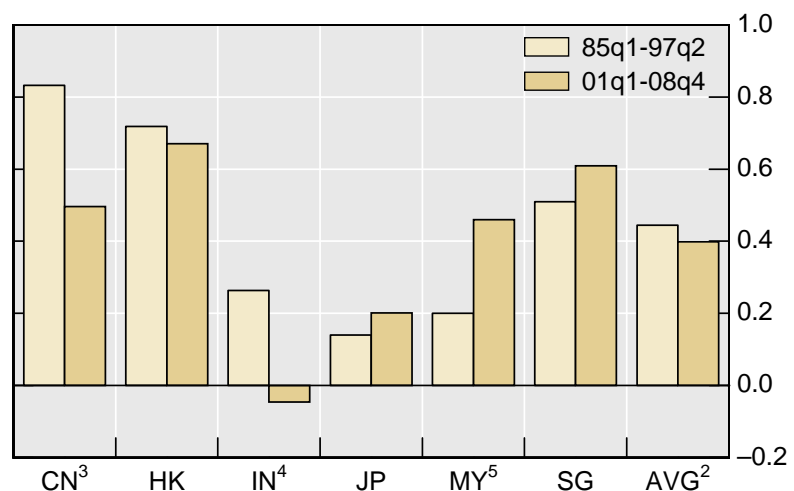

$\mathrm{AU}=$ Australia; $\mathrm{CN}=$ China; $\mathrm{HK}=$ Hong Kong; $\mathrm{ID}=$ Indonesia; $\mathrm{IN}=$ India; JP = Japan; $\mathrm{KR}=\mathrm{Korea} ; \mathrm{MY}=$ Malaysia; NZ = New Zealand; PH = Philippines; SG = Singapore; TH = Thailand.

${ }^{1}$ Estimated autoregressive coefficient for annualized quarter-on-quarter CPI inflation. ${ }^{2}$ Cross-country average coefficient. ${ }^{3}$ 93q2-97q2. ${ }^{4} 89 q 2-97 q 2 .{ }^{5} 85 q 2-97 q 2$.

Source: BIS calculations, national data.

\section{Graph 6}

\section{Changing IMA(1) inflation persistence ${ }^{1,2}$}

Inflation targeting

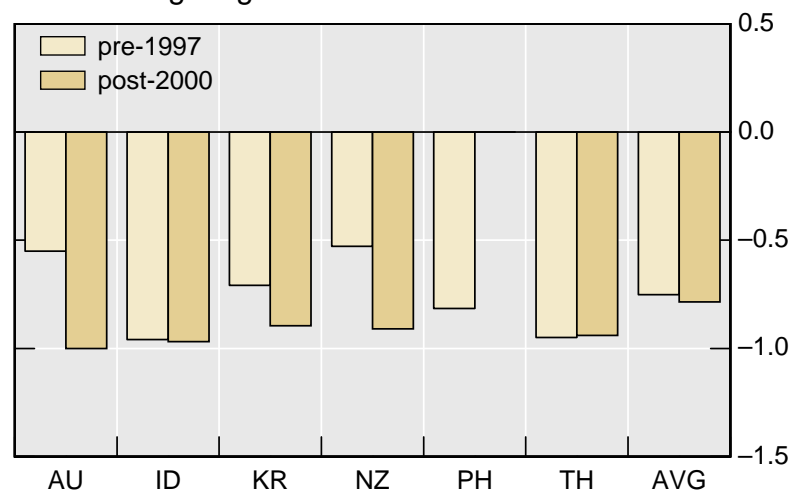

Non-Inflation targeting

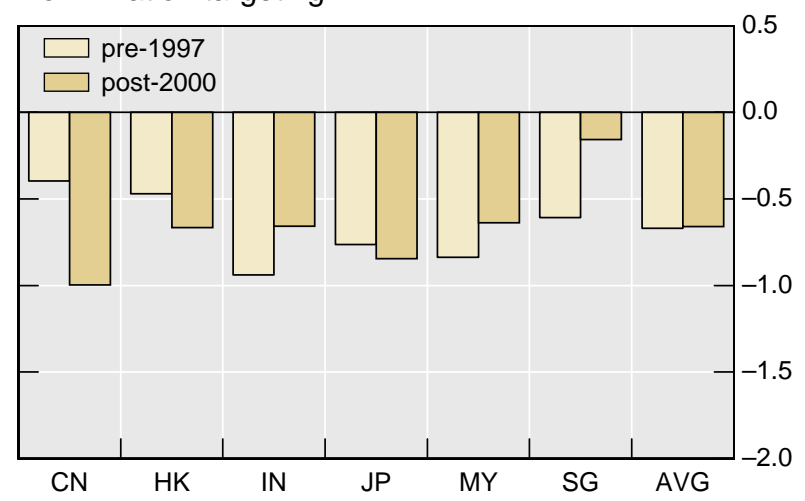

$\mathrm{AU}=$ Australia; $\mathrm{CN}=$ China; $\mathrm{HK}=$ Hong Kong; $\mathrm{ID}=$ Indonesia; $\mathrm{IN}=$ India; JP = Japan; $\mathrm{KR}=\mathrm{Korea} ; \mathrm{MY}=$ Malaysia; NZ = New Zealand; PH = Philippines; SG = Singapore; $\mathrm{TH}=$ Thailand.

${ }^{1}$ Estimated IMA(1,1) coefficient through unobserved components decomposition on the basis of 10 year sample subject to data availability. ${ }^{2}$ AVG stands for cross-country parameter mean.

Source: BIS calculations, national data. 


\section{Graph 7}

Cross-sectional distribution of next year's inflation expectations $\mathbf{s}^{1,2}$ Inflation targeting countries

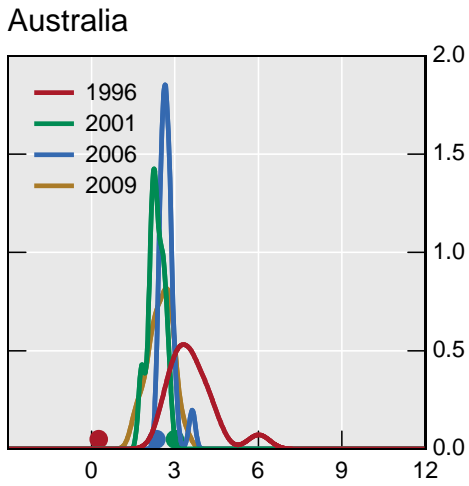

New Zealand

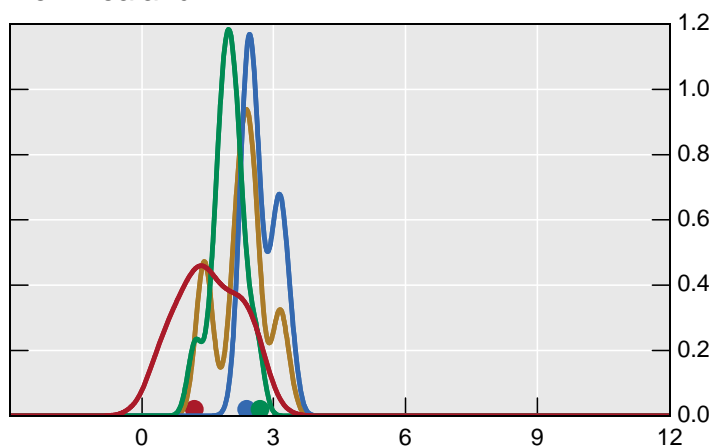

Indonesia

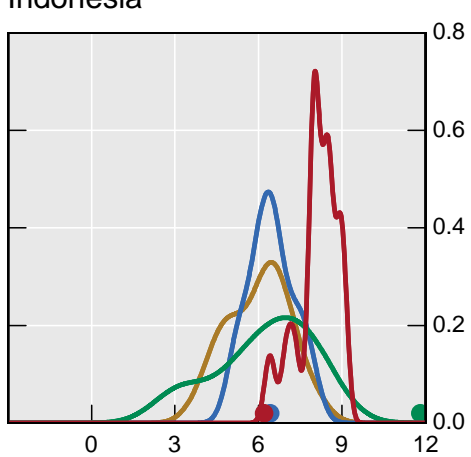

Thailand

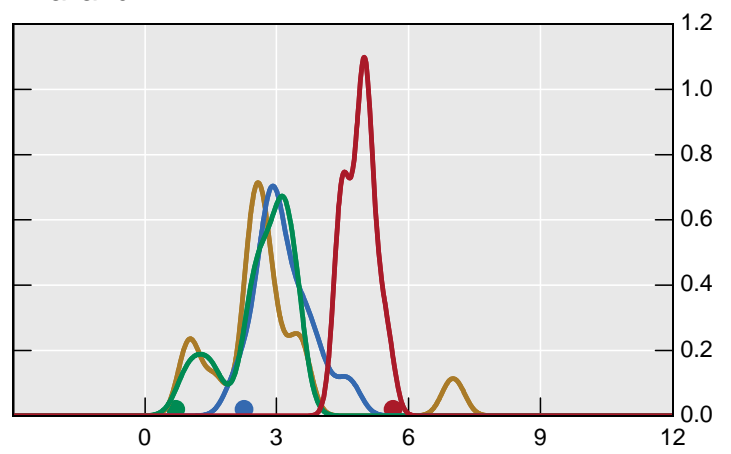

Korea

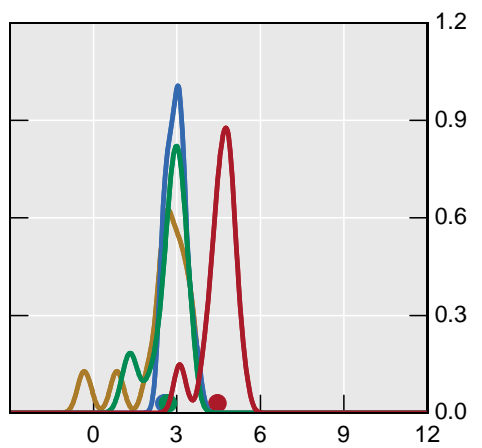

Non-inflation targeting countries

china

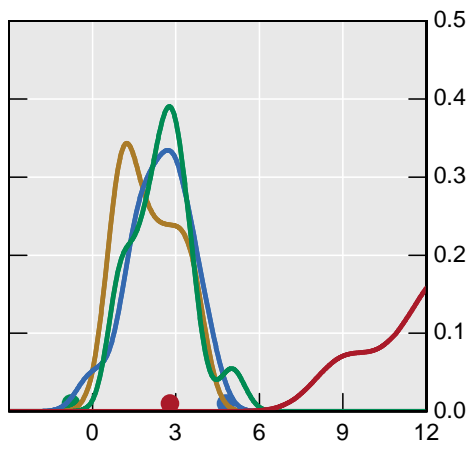

Japan

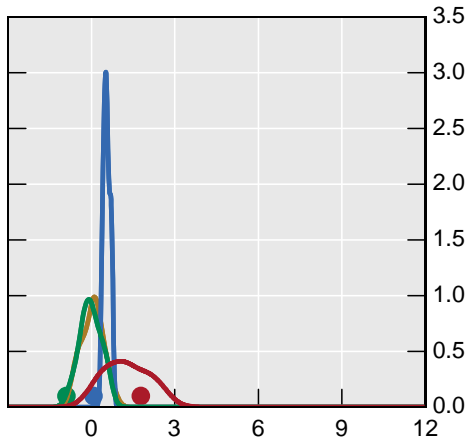

Hong Kong

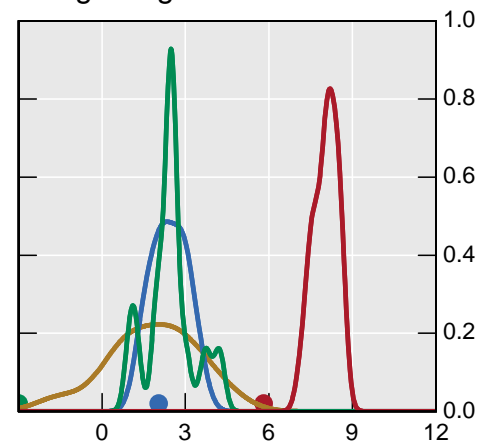

Malaysia

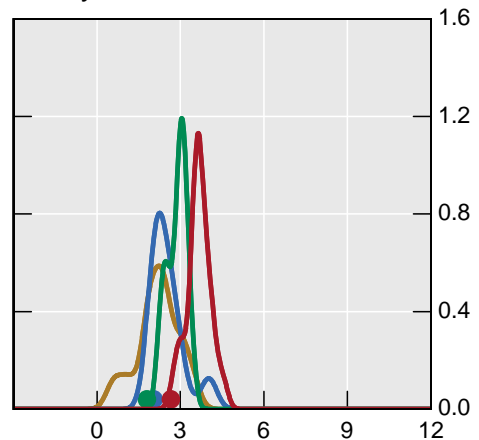

. 


\section{References}

Ashan, W, M Skully, and J Wickramanayake (2008): "Does central bank independence and governance matter in Asia Pacific?", Paolo Baffi Centre Research Paper Series No. 2008-27. http://papers.ssrn.com/sol3/papers.cfm?abstract_id=1263908.

Ball, L and N Sheridan (2003): "Does inflation targeting matter?", NBER Working Paper, no 9577, March.

Bernanke, B and F Mishkin (1997): "Inflation targeting: a new framework for monetary policy?" Journal of Economic Perspectives, Spring.

Committee on the Global Financial System (2009): "Capital flows and emerging market economies", CGFS Papers No 33, Bank for International Settlements, January.

Cuikerman, A, S B Webb, and B Nyapti (1992): "Measuring the independence of central banks and its effect on policy outcomes", World Bank Economic Review 6, pp 353-98.

Dincer, N and B Eichengreen (2007): "Central bank transparency: where, why and with what effect?", NBER Working Paper Series, no 13003, March.

Disyatat, P (2005): "Inflation targeting, asset prices and financial imbalances: conceptualizing the debate", BIS Working Papers, no 168, January.

Eijffinger, S and P Geraats (2006): "How transparent are central banks?" European Journal of Political Economy, March.

Filardo, A (2009): "Household debt, monetary policy and financial stability: still searching for a unifying model", in Proceedings of a joint conference organised by the BIS and the Bank of Korea in Seoul on 28 March 2008, BIS papers no 46, Bank for International Settlements, May.

Filardo, A and D Guinigundo (2008): "Transparency and communication in monetary policy: a survey of Asian central banks", forthcoming BIS Papers.

Fischer, S (2008): "The Phillips curve and Israeli monetary policy", a presentation at "Understanding inflation and the implications for monetary policy: a Phillips curve retrospective", A Conference Sponsored by the Federal Reserve Bank of Boston, Cape Cod, Massachusetts, 9-11 June.

Fry, M (1996): "Governance at the macro level: assessing central bank independence in Pacific Asia and other developing areas", Department of Economics Discussion Papers, University of Birmingham.

Garcia-Herrero, A and E Remolona (2008): "Managing expectations by words and deeds: monetary policy in Asia and the Pacific", forthcoming BIS Papers.

Genberg, H and D He (2009): "Monetary and financial cooperation among central banks in East Asia and the Pacific", in R Rajan, S Thangavelu and R Parinduri (eds), Exchange Rate, Monetary and Financial Issues and Policies in Asia, Singapore, World Scientific Publishing Co, pp $247-70$.

Greenspan, A (2002): "Transparency in monetary policy", Federal Reserve Bank of St. Louis Review, July/August.

Mishkin, F and K Schmidt-Hebbel (2006): "Does inflation targeting make a difference?", Central Bank of Chile Working Papers no. 404, December.

Stock, J and M Watson (2007): "Why has US inflation become harder to forecast?", Journal of Money, Credit and Banking, February.

Svensson, L (2003): "Monetary policy and real stabilization", in Rethinking Stabilization Policy, A Symposium Sponsored by the Federal Reserve Bank of Kansas City, Jackson Hole, Wyoming, 29-31 August. 
Woodford, M (2003): Interest and prices, Princeton University Press.

Woodford, M (2005): "Central bank communication and policy effectiveness", in The Greenspan Era: Lessons for the Future, A Symposium Sponsored by the Federal Reserve Bank of Kansas City, Jackson Hole, Wyoming, 25-27 August. 